\title{
Études irlandaises
}

\section{The Fall of the House of Paisley}

\section{Michel Savaric}

\section{(2) OpenEdition}

Journals

\section{Édition électronique}

URL : http://journals.openedition.org/etudesirlandaises/2095

DOI : 10.4000/etudesirlandaises.2095

ISSN : 2259-8863

\section{Éditeur}

Presses universitaires de Caen

\section{Édition imprimée}

Date de publication : 30 décembre 2010

Pagination : 199-201

ISBN : 978-2-7535-1246-7

ISSN : 0183-973X

\section{Référence électronique}

Michel Savaric, "The Fall of the House of Paisley », Études irlandaises [En ligne], 35-2 | 2010, mis en ligne le 30 décembre 2010, consulté le 21 septembre 2020. URL : http://journals.openedition.org/ etudesirlandaises/2095; DOI : https://doi.org/10.4000/etudesirlandaises.2095

Ce document a été généré automatiquement le 21 septembre 2020.

\section{(c) (i) (2)(2)}

Études irlandaises est mise à disposition selon les termes de la Licence Creative Commons Attribution - Pas d'Utilisation Commerciale - Partage dans les Mêmes Conditions 4.0 International. 


\title{
The Fall of the House of Paisley
}

\author{
Michel Savaric
}

\section{RÉFÉRENCE}

David Gordon, The Fall of the House of Paisley, Dublin, Gill \& Macmillan, 2009, Revised edition 2010, 267 p., ISBN 978-0-7171-4830-1

1 Pour tous les observateurs de l'époque, lorsqu'il est apparu sur la scène politique d'Irlande du Nord en 1964, Ian Paisley faisait figure d'anachronisme. Sa rhétorique antipapiste semblait surgir tout droit du dix-septième siècle (ou peut-être, plus proche de nous, du renouveau évangélique protestant du milieu du dix-neuvième siècle). Ian Paisley était un outsider, il ne faisait pas partie de l'establishment unioniste et, à ce titre, il prétendait incarner les intérêts et les revendications de la classe ouvrière loyaliste. En mai 2010, âgé de 84 ans, il est devenu Lord. Pendant plus de 40 ans, il a incarné l'intransigeance et la rectitude protestantes. Il est entré dans le folklore populaire (voir les fameuses Paisley jokes par exemple). Celui qui avait dit «never, never, never, never " à Margaret Thatcher après la signature de l'Accord anglo-irlandais affirmait encore, le 12 juillet 2006, que le Sinn Féin entrerait au gouvernement «over our dead bodies ». Huit mois plus tard, il apparaissait, tout sourire, en compagnie de Gerry Adams pour une conférence de presse. En mai 2007, il gouvernait l'Irlande du Nord en compagnie de Martin McGuinness, ancien chef d'État-major de l'IRA entre 1978 et 1982 !

2 Cet ouvrage de David Gordon, journaliste au Belfast Telegraph, est consacré à cet invraisemblable revirement. De nombreux commentateurs ont choisi de célébrer la transformation de l'intraitable puritain Ian Paisley en «homme de paix ». Telle n'est pas l'option choisie par David Gordon. Son regard est plutôt un regard critique, teinté d'ironie, sur la consécration, puis la chute, de Paisley père et fils, installés aux commandes de l'Irlande du Nord de mai 2007 à février et mars 2008. Au passage, l'ouvrage dresse une chronique de la vie politique de l'Irlande du Nord pendant ces quelques mois. 
Il détaille les réactions des fidèles de Paisley lorsqu'ils le virent riant à gorge déployée avec son acolyte du Sinn Féin : choc, incrédulité, sentiment d'avoir été trahi par celui-là même qui ne cessait de mettre en garde contre les "Lundies", les traîtres. Les dissensions au sein de son Église presbytérienne libre conduisirent Ian Paisley à laisser sa place de «Moderator». À la tête du gouvernement, les « affaires » se sont accumulées. Celles-ci concernaient avant tout les liens entre la famille Paisley et un promoteur immobilier de la côte nord d'Antrim du nom de Seymour Sweeney, lui-même membre du DUP. En particulier, Ian Paisley Jr a tout fait pour favoriser l'adoption d'un projet pharaonique de centre touristique sur le site de la célèbre Chaussée des Géants. Encourant l'ire du National Trust et de l'UNESCO, les tentatives de Paisley Jr ne pouvaient aboutir. Néanmoins, il n'a pas ménagé ses efforts et son temps pour les faire aboutir.

D'autres affaires ont émergé grâce à Gordon lui-même, notamment la location de bureaux somptueux et immenses par le DUP dans le centre de Ballymena. Le loyer payé par l'État, grossièrement surévalué s'élevait à $£ 62000$ et le propriétaire s'avérait être nul autre que Sweeney! Ces scandales à répétition ont eu un effet dévastateur pour le DUP. En février 2008, alors qu'il s'attendait à remporter sans effort l'élection partielle de Dromore, le parti connut une humiliante défaite. Quelques jours plus tard, Ian Jr a annoncé sa démission; personne au sein de son parti n'a cherché à prendre sa défense. Le père et le fils fonctionnant en tandem, Ian senior a annoncé son départ à la retraite le mois suivant alors qu'il jurait quelques semaines plus tôt de son désir de mener son mandat jusqu'à son terme.

5 Malgré quelques répétitions, l'ouvrage de David Gordon est écrit sur un ton dynamique tout en détaillant bien les questions qu'il traite. En refermant le livre, on ne peut s'empêcher de partager les interrogations de David Trimble sur Paisley, citées par Gordon: "Dr Paisley hasn't made it clear why Sinn Féin's Martin McGuinness is his number two - a man with a terrorist past - yet he criticised me for working alongside people like constitutional nationalist Seamus Mallon, my extremely able Deputy First Minister. It has been suggested that Ian Paisley and his colleagues found themselves in power after 40 years on the sidelines, and embraced it with both arms. Perhaps he always wanted to be Prime Minister of Northern Ireland at whatever cost - I pose the question which only he can answer. "

6 La fin de la carrière politique de Paisley soulève bien des questions sur toute la période des Troubles pendant laquelle il a joué un rôle prépondérant. Le sujet est loin d'être épuisé et la question posée par Trimble pourrait aussi très certainement s'appliquer à Gerry Adams et Martin McGuinness. 